\title{
Trends of publications related to climate change and lake research from 1991 to 2015
}

\author{
Jianming DENG, ${ }^{1}$ Yunlin ZHANG, ${ }^{1 *}$ Boqiang QIN, ${ }^{1 *}$ Xiaolong YAO,${ }^{1,2}$ Yubing DENG ${ }^{3}$ \\ ${ }^{1}$ Taihu Laboratory for Lake Ecosystem Research, State Key Laboratory of Lake Science and Environment, Nanjing Institute of \\ Geography and Limnology, Chinese Academy of Sciences, Nanjing 210008; ${ }^{2}$ University of Chinese Academy of Sciences, Beijing \\ 100049; ${ }^{3}$ College of Resources \& Environment, GIS Research Center, Hunan Normal University, Changsha 410006, China \\ *Corresponding authors: qinbq@niglas.ac.cn; ylzhang@niglas.ac.cn
}

\begin{abstract}
Climate change has been studied for many decades. Growing scientific, political, and public attention has focused on climate change and its effect on ecosystems, including lake ecosystems. In this study, we conducted comparative quantitative and qualitative analyses that focused on research development, current hotspots, and potential future directions of climate change research associated with lakes using a bibliometric analysis based on the Science Citation Index (SCI) database. A total of 10,296 papers associated with climate change-lake research were published in 1266 journals. Rapid development occurred over the past 25 years and the number of published papers considerably increased since the 2000s. A keyword analysis showed that among the top 50 most frequently used keywords, paleoecology, palynology, paleolimnology, climate change, and pollen analysis exhibited decreasing trends. Recently, eutrophication exhibited one of the highest co-occurrence frequencies with climate change. Keywords such as algae and cyanobacteria also showed increasing trends with climate change, implied that more attention was paid to the harmful cyanobacterial blooms. Another significant increasing trend was observed between climate change and remote sensing, which is a modern technology that is now widely used in limnology. Our results also indicate that a distinct turning point associated with climate change-lake research occurred between 1991 and 2015. Before the 2000s, most studies focused on paleolimnology. Specifically, researchers were searching for the evidence of climate change in lake sediments by using traditional technologies, such as reflecting ancient climate using the information recorded by diatom or pollen in the sediments. Recently, more studies have focused on modern limnology, e.g., the effects of climate change on lake ecosystems. In addition, future research may focus on the following topics: i) the interactive effects of climate change and eutrophication, or other environmental variables, on lake ecosystems; ii) solutions for mitigating the negative effects of climate change; and iii) the potential effects of eutrophication on climate change.
\end{abstract}

Key words: Author keyword; bibliometric analysis; current hots; future directions.

Received: December 2016. Accepted: February 2017.

\section{INTRODUCTION}

Climate change, specifically global warming, has become a major scientific, political, economic, and environmental issue in recent decades (Walther et al., 2002; Stocker et al., 2013). With the large and strongly growing amount of climate change research literature, bibliometric method could be used to describe the latest advances in climate change research (Li et al., 2011). Based on bibliometrics, it was concluded that research dealing with adaptation, mitigation, risks, and vulnerability of global warming is comparatively small, but their share of papers increased exponentially since 2005 (Haunschild et al., 2016). Other bibliometric studies concluded that the items "temperature", "environment", "precipitation", "greenhouse gas", "risk", and "biodiversity" will be the foci of climate change research in the $21^{\text {st }}$ century, while "model", "monitoring", and "remote sensing" will continue to be the leading research methods. Bibliometrics refers to indicators of scientific output based on the numbers of publications in international journals (van Raan, 1996), and has been applied to assess the scientific outputs or research patterns of authors, journals, countries, and institutes and to identify and quantify international cooperation (Li and Zhao, 2015). As a rapidly developing quantitative method, bibliommmetrics is also useful analyzing the history of science (Marx et al., 2017). It was first introduced by Pritchard (Pritchard, 1969), has been used in many disciplines of science and engineering to measure scientific progress and is a common research instrument for systematic analysis (van Raan, 2009).

However, few bibliometric studies reviewed the studies about climate change related to lakes. Previous studies have suggested that lakes effectively represent global climate change because they are sensitive to environmental changes, and some climate-related signals are highly visible and easily measurable in lakes (Carpenter et al., 2007; Pham et al., 2008; Adrian et al., 2009). Paleolimnological records, in particular, have been used to develop climate records over recent geologic timescales, allowing us to interpret current climate change and predict its effects. Hence, historical diatoms, chironomids and pollens deposited in lake sediments are crucial paleoclimate information carriers. 
Meanwhile, lake ecosystems are vulnerable to climate change. Previous researches have studied thermal stratification (Posch et al., 2012), nutrients (Jensen and Andersen, 1992; Jeppesen et al., 2009, 2011), phytoplankton and zooplankton (Adrian et al., 2009), cyanobacterial blooms (Jöhnk et al., 2008; Wagner and Adrian, 2009; Paerl and Paul, 2012) in response to climate change. Other prevalent topics include the technology and methodology used in climate change studies in/of lakes. The methods included classical paleolimnology, models (Komatsu et al., 2007), and the new rising method such as remote sensing (Duan et al., 2009; Zhang et al., 2012).

However, the subject of climate change associated with lakes is vast. In order to study the global and temporal trends of climate change associated with lake research, this paper used a bibliometric method (Ellegaard and Wallin, 2015 ) to measure the scientific progress of climate change studies that have focused on lakes over the past 25 years (1991-2015). The analysis results can help to better understand the global trends of climate change and lake research and reveal underlying patterns in scientific outputs, pinpointing subject-specific research. More specifically, the aims of this study are as follows: i) reveal the current climate change hotspots associated with lake research based on a keyword analysis; and ii) discuss future research directions, serving as a potential guide for future research.

\section{METHODS}

The SCI-Expanded database is the most comprehensive and frequently used data source in bibliometrics (Ho and Kahn, 2014). It is used to review high-quality publications and assess scientific development, current hotspots, and future research directions (Khan and Ho, 2012; Zhi and Ji, 2012; Barbosa and Schneck, 2015). The SCI-Expanded database included 11,149 major journals with citation references across 237 scientific disciplines distributed in 82 countries in 2015.

The data were based on the online version of SCI-Expanded, called the Web of Science, spanning from 1991 to 2015. We built our bibliometric database on 24 January, 2017 based on the ISI Web of Science, which is the most frequently used and most robust database for bibliometric studies (Liu et al., 2011). We selected documents that contained the descriptors "climate change" and "lake" in the topic section (TS):

TS = ("climat* chang*" or "climat* warm*" or "global chang*" or "global warm*") and "lake*".

This search strategy allowed us to locate publications that contained the abovementioned search terms in their titles, abstracts, keywords or keywords plus. Publications originating from England, Scotland, Northern Ireland, and Wales were grouped under the UK heading, and publications from Hong Kong, Macao, and Taiwan were not grouped under the heading of China.

We then extracted information from each publication, including the author name and affiliation, document type, publishing language, journal name, publication year, geographic coordinate, and keywords. Because some databases abbreviated author names in their earlier stages, different authors could be mistakenly recognized as the same author. Thus, we compared their institutions to identify the authors. This still has potential limitation, as during the studied time frame of 25 years it is very likely that scientists change their institutional affiliation. Hence, only top 20 authors were paid attention to in detail analysis in order to reduce the flaws in our study.

First, we generally presented the publication number, country, and journal distribution trends in each year (Fig. 1). Then, we analyzed the author-used keywords, as keywords provide important information about research trends and topics, revealing areas of research interest (Ho, 2007). The analysis included the most frequent keywords and their trends, their co-occurrence with each other, the most productive authors, and their co-occurrence with keywords. When analyzing the research topics, author keywords were retrieved directly, as they contain the most critical information in most articles. Different words with identical meanings were grouped and considered a single keyword. The temporal and interactive characteristics of the articles, authors, and keywords are presented using time series [Mann-Kendall trend test (Salmaso, 2011)], frequency, and co-occurrence analyses. Microsoft Excel 2016 was used for general data manipulation. Statistical analyses were carried out with $\mathrm{R}$ version 3.2 (R Core Team, 2015) and the figures were drawn either by $R$ version 3.2 or Excel 2016. In particular, Mann-Kendall trend analyses were carried out using "Kendall" (McLeod, 2011), and network analyses and visualization were carried out with "igraph" (Csardi and Nepusz, 2006).

\section{RESULTS}

\section{Publication outputs}

Using the above search strategy, 10,296 publications were identified (data from 2015 may be incomplete due to databases lag). There has been a stable increase in climate change studies related to lake research over the past 25 years. The annual number of papers increased from 53 in 1991 to 1145 in 2015. The document type was dominated by articles, which accounted for $82.9 \%$ of all publications. The number of articles increased steadily from 1991-2015. A less-significant portion was comprised of proceeding papers (5.8\%) and reviews (5.54\%). Most of the publications were published in English $(10,211 ; 99.2 \%)$, and the next most popular language was French $(32 ; 0.31 \%)$.

\section{Journal distribution}

Articles were published in a wide range of 1266 journals, the top 50 journals published most papers was summarized in Tab. 1. In this particular research field, 
Quaternary Science Reviews published the most articles (495; $4.85 \%$ ), while the Journal of Paleolimnology ranked second with 421 (4.13\%), Palaeogeography Palaeoclimatology Palaeoecology ranked third with 405 (3.97\%), and Holocene ranked fourth with 367 (3.6\%). Quaternary International was ranked just behind Holocene with 317 (3.11\%). The percentage of the most popular journal was not high, indicating the breadth of article distribution in lake-climate change research, as well as the broad interest in lake-climate change research from various fields.

There were 14 journals with contributions greater than $1 \%$ of the total papers (Tab. 1). Among the 14 journals, most focus on paleolimnology. For instance, as indicated by the aims and scope of the journals, the most fruitful journal, Quaternary Science Reviews, covered all aspects of Quaternary science, including geology, geomorphology, geography, archaeology, soil science, paleobotany, paleontology, paleoclimatology, and the full range of applicable dating methods. The second most popular journal, Journal of Paleolimnology, provides a vehicle for the rapid dissemination of original scientific work dealing with the reconstruction of lake histories. Palaeogeography Palaeoclimatology Palaeoecology included multidisciplinary and original studies or reviews in the field of palaeo-environmental geology, including paleoclimatology. Of the top 14 journals, only five mainly focused on modern limnology, e.g., the effects of climate change on aquatic ecosystems.

The number of publications each year exhibited increasing tends for most of the journals, and only four exhibited decreasing trends recently, including the Journal of Paleolimnology, Quaternary Research, Journal of Quaternary Science, and Limnology and Oceanography.
Notably, according to the percentage of publications in each journal compared to the total publication numbers each year, the ratios of most journals recently displayed decreasing trends or remained stable (Fig. 2), except Freshwater Biology and the Journal of Great Lakes Research. The publication trends of each journal may suggest that more studies related to the effects of climate change on lake ecosystems are being conducted currently.

\section{Author-used keywords}

Of the 10,296 papers, 3050 papers had no author keywords, and there are peculiarities when related to journal statistic. For instance, Quaternary Science Reviews have 257 papers (51.9\% of total papers in this journal and 2.5\% of total papers) without author keywords, followed by Quaternary International, there were 255 papers without author keywords ( $80.4 \%$ and $2.48 \%$ respectively). Papers in the journals such as Limnology and Oceanography, Canadian Journal of Fisheries and Aquatic Sciences, PLoS One, Environmental Science \& Technology, Arctic Antarctic and Alpine Research, et al., did not contained author used keywords. The remaining 7246 papers contained 16,311 author keywords. Of these keywords, $12,303(75.37 \%)$ appeared just once, $1750(10.72 \%)$ were used twice, (726 appeared 3 times, 393 four times, 243 five times, 170 six times, 108 seven times, 78 eight times, 67 nine times, 37 ten times) and only $436(2.67 \%)$ keywords appeared in more than 10 papers (Tab. 2). The top 50 most frequently used keywords are summarized in Tab. 3. The trends associated with each of the top 50 keywords were evaluated using a Mann-Kendall trend test.

Five of the 50 keywords exhibited decreasing trends

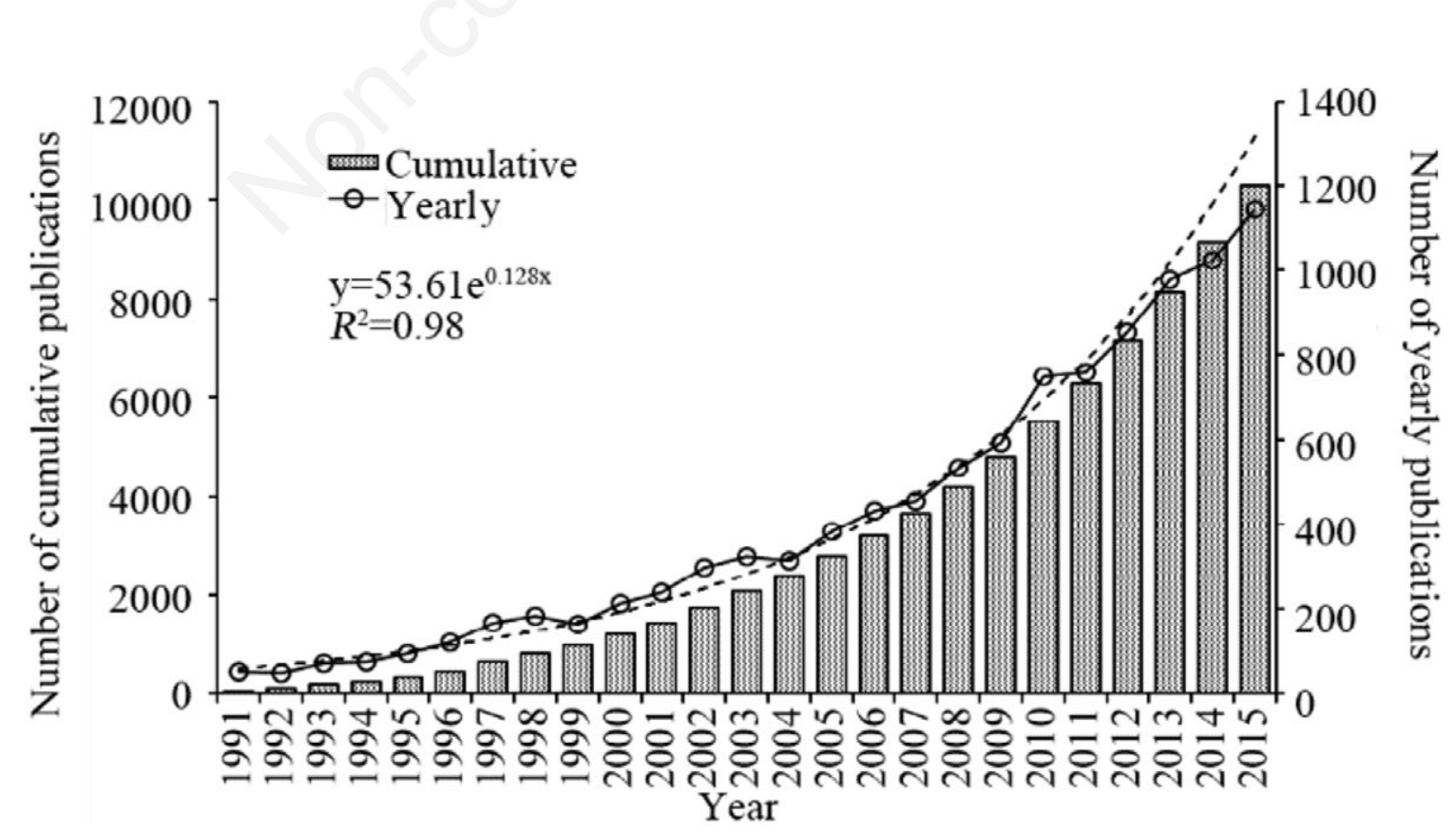

Fig. 1. Cumulative and yearly publication numbers and growth trend in the field of climate change research related to lakes. 
over the past 25 years. The most significant were paleoe$\operatorname{cology}(\tau=-0.58, \mathrm{P}<0.001)$ and palynology $(\tau=-0.55$, $\mathrm{P}<0.001)$, followed by paleolimnology $(\tau=-0.38$, $\mathrm{P}<0.01)$. The last two were climate change $(\tau=-0.37$, $\mathrm{P}<0.05)$ and pollen analysis $(\tau=-0.34, \mathrm{P}<0.05)$. The decreasing trends associated with palynology and pollen analysis may indicate that studies that reconstruct paleoclimate have begun to abandon the use of pollen.

Compared to these decreasing trends, 12 keywords displayed increasing trends from 1991 to 2015. These 12 keywords were related to the study area (Tibetan Plateau, $\tau=0.66, \mathrm{P}<0.001$; permafrost, $\tau=0.51, \mathrm{P}<0.001$ ), study object and topic (cyanobacteria, $\tau=0.62, \mathrm{P}<0.001$; $n u$ trients, $\tau=0.53, \mathrm{P}<0.001$; phosphorus, $\tau=0.48, \mathrm{P}<0.01$; eutrophication, $\tau=0.4, \mathrm{P}<0.01$; zooplankton, $\tau=0.37$,
$\mathrm{P}<0.05$; phytoplankton, $\tau=0.3, \mathrm{P}<0.05)$, study time scale (Late Holocene, $\tau=0.41, \mathrm{P}<0.01$ ), method used (remote sensing, $\tau=0.61, \mathrm{P}<0.001$; chironomids, $\tau=0.35$, $\mathrm{P}<0.05$ ), and others (precipitation, $\tau=0.5, \mathrm{P}<0.001$ ).

Every keyword was included and ranked for each 5year interval from 1991-2015. Furthermore, we created a cross-correlation matrix based on the top 50 keywords and performed a co-occurrence analysis. The results are shown in Fig. 3. The sizes of the nodes are proportional to the occurrence frequencies of keywords. The lines represent the relationship between two words, and the connection strength is shown by the thickness and color.

The relationships among the keywords were intricate. However, climate change has always been the center node. During 1991 and 1995, in addition to lake, climate

Tab. 1. The top 50 journals published the most papers and the percentage to total papers.

\begin{tabular}{|c|c|c|c|}
\hline Journals & Percentage $(\%)$ & Journals & Percentage (\%) \\
\hline Quaternary Science Reviews & 4.85 & PNAS & 0.66 \\
\hline Journal of Paleolimnology & 4.13 & Environmental Science \& Technology & 0.65 \\
\hline Palaeogeography Palaeoclimatology Palaeoecology & 3.97 & Arctic Antarctic and Alpine Research & 0.64 \\
\hline Holocene & 3.6 & Chinese Science Bulletin & 0.64 \\
\hline Quaternary International & 3.11 & Climate of the Past & 0.61 \\
\hline Quaternary Research & 2.72 & Water Resources Research & 0.6 \\
\hline Hydrobiologia & 2.28 & Vegetation History and Archaeobotany & 0.59 \\
\hline Journal of Quaternary Science & 1.6 & Journal of Geophysical Research-Biogeosciences & 0.57 \\
\hline Freshwater Biology & 1.58 & Journal of Biogeography & 0.56 \\
\hline Global and Planetary Change & 1.4 & Review of Palaeobotany and Palynology & 0.55 \\
\hline Limnology and Oceanography & 1.29 & Ecological Modelling & 0.53 \\
\hline Global Change Biology & 1.24 & Hydrology and Earth System Sciences & 0.53 \\
\hline Journal of Great Lakes Research & 1.19 & Journal of Geophysical Research-Atmospheres & 0.51 \\
\hline Climatic Change & 1.08 & Nature & 0.5 \\
\hline Journal of Hydrology & 0.93 & Journal of Limnology & 0.46 \\
\hline Canadian Journal of Fisheries and Aquatic Sciences & 0.89 & Remote Sensing of Environment & 0.42 \\
\hline PLoS ONE & 0.89 & Biogeosciences & 0.42 \\
\hline Hydrological Processes & 0.89 & Environmental Earth Sciences & 0.41 \\
\hline Science of the Total Environment & 0.88 & Ambio & 0.4 \\
\hline Geomorphology & 0.87 & Biogeochemistry & 0.39 \\
\hline Geophysical research letters & 0.87 & Aquatic Sciences & 0.36 \\
\hline Boreas & 0.85 & Oecologia & 0.35 \\
\hline Ecology & 0.77 & Science & 0.35 \\
\hline Geology & 0.76 & Geological Society of America Bulletin & 0.33 \\
\hline Earth and Planetary Science Letters & 0.75 & Climate Dynamics & 0.31 \\
\hline
\end{tabular}

Tab. 2. Occurrence of the author used keywords and their percentage to total keywords.

\begin{tabular}{lccccccccccc} 
Times & 1 & 2 & 3 & 4 & 5 & 6 & 7 & 8 & 9 & 10 & $>10$ \\
Keywords & 12,303 & 1750 & 726 & 393 & 243 & 170 & 108 & 78 & 67 & 37 & 436 \\
\hline Percentage (\%) & 75.43 & 10.73 & 4.45 & 2.41 & 1.49 & 1.04 & 0.66 & 0.48 & 0.41 & 0.23 & 2.67 \\
\hline
\end{tabular}


change exhibited strong relationships with temperature, diatom, little ice age, Late Quaternary, human activities, vegetation, palynology, and Holocene. This may suggest a wide range of research interests during this five-year period. During 1996 and 2000, climate change exhibited strong relationships with Holocene, paleolimnology, and diatom. From 2001 until 2005, in addition to these three keywords, climate change was strongly related to pollen. Both diatom and pollen in lake sediments were widely used in paleolimnology. The increasing importance of pollen from 2001 to 2005 indicated that pollen was widely used to reconstruct paleoclimates during this period. During 2006 and 2010, climate change was still strongly related to Holocene and diatom, followed by lake. Although few keywords exhibited strong relationships with climate change, other keywords such as temperature, eutrophication, pollen, human activities, paleolimnology, lake sedi- ments, and paleoclimate were highly related to climate change, as indicated by light blue lines in Fig. 3. This may suggest a wide range of research interests during this fiveyear period. From 2011 to 2015, climate change was strongly related to Holocene, eutrophication, and lake. Keywords such as pollen, human activities, cyanobacteria, algae, diatom, paleolimnology, and paleoecology also displayed notable relationships with climate change.

Notably, during 1991 and 1995, the keywords freshwater and eutrophication were separated from others. However, during 2011 and 2015, eutrophication exhibited one of the highest co-occurrence frequencies with climate change. Keywords such as algae and cyanobacteria also showed increasing trends with climate change. Another significant increasing trend was observed between climate change and remote sensing, which is a modern technology that is now widely used in limnology.

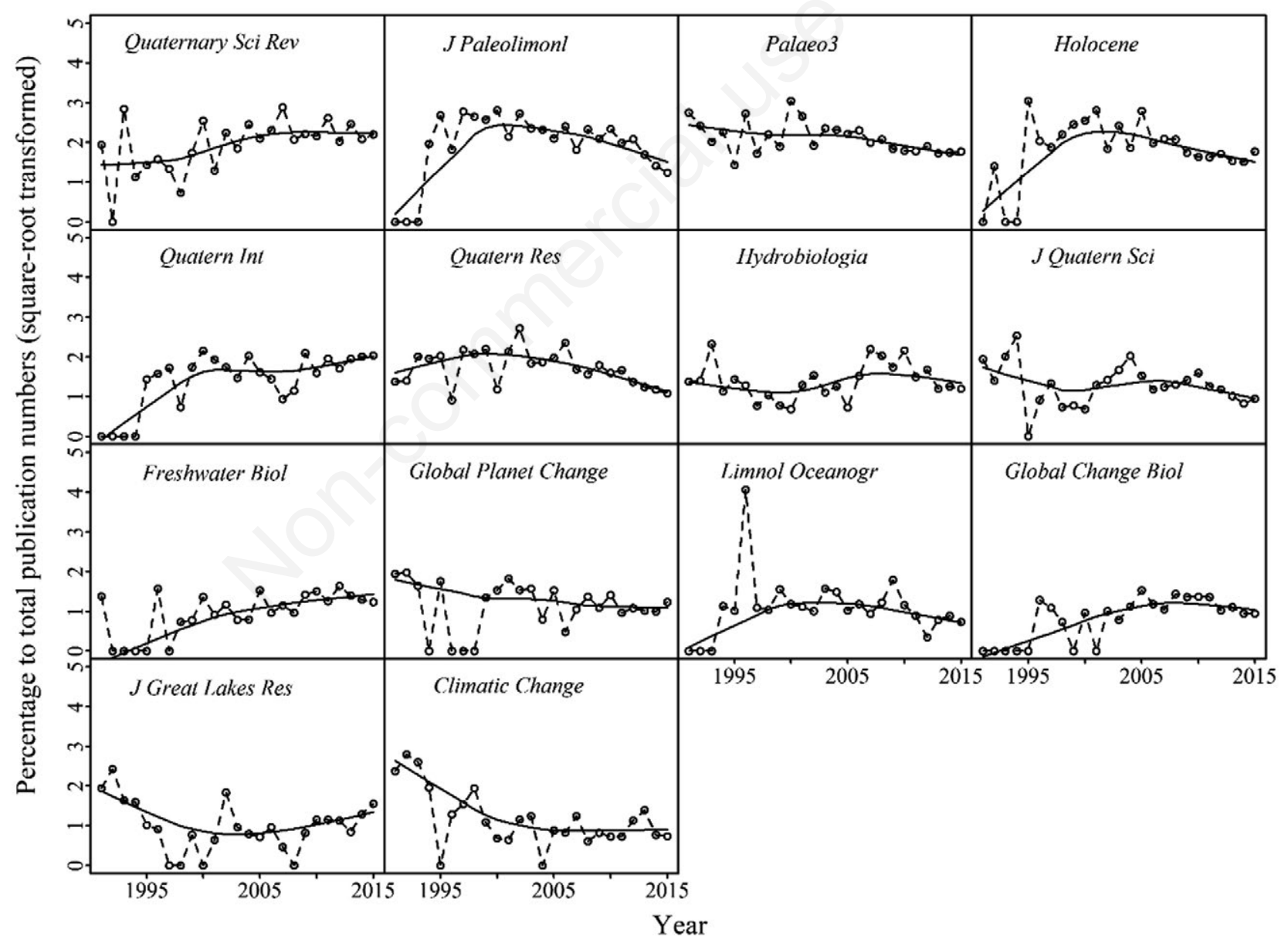

Fig. 2. Ratio of publications in the top 14 journals to total publications each year during the study period. Quaternary Sci Rev, Quaternary Science Reviews; J Paleolimonl, Journal of Paleolimnology; Palaeo3, Palaeogeography Palaeoclimatology Palaeoecology; Holocene, Holocene; Quatern Int, Quaternary International; Quatern Res, Quaternary Research; Hydrobiologia, Hydrobiologia; Freshwater Biol, Freshwater Biology; J Quatern Sci, Journal of Quaternary Science; Global Planet Change, Global and Planetary Change; Limnol Oceanogr, Limnology and Oceanography; Global Change Biol, Global Change Biology; J Great Lakes Res, Journal of Great Lakes Research; Climatic Change, Climatic Change. 


\section{Author distribution}

Of the 10,296 publications, 29,136 authors were recorded. However, most $(28,336,97.3 \%)$ authored less than five publications. The 20 most productive authors are listed in Tab. 4. John P. Smol from the Department of Biology, Paleoecological Environmental Assessment and Research Lab at Queen's University, Canada contributed the most articles (135 papers), followed by Erik Jeppesen from Aarhus University (76 papers). The number of publications published as the first author was also counted. Although J.P. Smol was the most productive author, he only published eight articles as the first author.

According to the relationships between authors and keywords, we extrapolated their research interests. As indicated in Fig. 4, most of the researchers focused on paleolimnology or paleoclimate. However, their study methods or areas may differ. For instance, Smol studied both chironomids and diatoms, mainly focusing on Arctic lakes. Studies from Briks focused on paleoclimate inversion using transfer functions based on information extracted from chironomids, pollen, and diatoms de- posited in lake sediments. Other studies, such as studies from Leng, used isotopes to study paleoclimate. Studies from Jeppesen and Søndergarrd focused on the effects of climate change on eutrophication. Additionally, the number of publications by each productive author was calculated for each year from 1991 to 2015, and its ratio based on the total publications in each year is shown in Fig. 5. The Smol's percentage exhibited a significant decreasing trend from 2000 to 2015. Similarly, the percentages of Briks, Pienitz, Battarbee, and Wolfe displayed decreasing trends in recent years as well. The percentages of both Jeppesen and Søndergaard have exhibited increasing trends since 2000. Trends of other authors showed unimodal shapes from 1991 to 2015.

\section{DISCUSSION}

Our results indicated increasing trends associated with climate change studies of lakes from 1991 to 2015 according to the increasing publication numbers (Larsen and Ins, 2010). The publication output data demonstrated that cli-

Tab. 3. The top 50 keywords and their trends during 1991 and 2015.

\begin{tabular}{|c|c|c|c|c|c|c|c|}
\hline Keywords & Rank & Mean \pm SD & Trend $^{\circ}$ & Keywords & Rank & Mean \pm SD & Trend $^{\circ}$ \\
\hline Paleoecology & 9 & $0.51 \pm 0.39$ & $-0.58 * * *$ & Wetlands & 22 & $0.27 \pm 0.37$ & 0.08 \\
\hline Palynology & 23 & $0.26 \pm 0.38$ & $-0.55 * * *$ & Great Lakes & 41 & $0.18 \pm 0.38$ & 0.09 \\
\hline Paleolimnology & 6 & $0.81 \pm 0.71$ & $-0.38 * *$ & Lake & 7 & $0.78 \pm 0.28$ & 0.11 \\
\hline Climate change & 1 & $6.10 \pm 1.84$ & $-0.37^{*}$ & Temperature & 10 & $0.44 \pm 0.29$ & 0.11 \\
\hline Pollen analysis & 19 & $0.30 \pm 0.36$ & $-0.34 *$ & Vegetation & 34 & $0.02 \pm 0.30$ & 0.13 \\
\hline Diatoms & 4 & $0.94 \pm 0.59$ & -0.28 & DOC & 37 & $0.19 \pm 0.17$ & 0.13 \\
\hline Quaternary & 28 & $0.22 \pm 0.27$ & -0.26 & Freshwater & 46 & $0.17 \pm 0.20$ & 0.14 \\
\hline Vegetation history & 29 & $0.22 \pm 0.31$ & -0.26 & Little Ice Age & 42 & $0.18 \pm 0.29$ & 0.18 \\
\hline Paleoclimate & 3 & $0.94 \pm 0.61$ & -0.21 & Oxygen isotopes & 49 & $0.16 \pm 0.14$ & 0.2 \\
\hline Holocene & 2 & $1.91 \pm 0.79$ & -0.21 & Fire history & 40 & $0.18 \pm 0.17$ & 0.21 \\
\hline Lake sediments & 8 & $0.72 \pm 0.34$ & -0.16 & Arctic & 16 & $0.32 \pm 0.19$ & 0.22 \\
\hline Late glacial & 32 & $0.21 \pm 0.21$ & -0.09 & Geochemistry & 26 & $0.23 \pm 0.15$ & 0.26 \\
\hline Stable isotopes & 14 & $0.35 \pm 0.29$ & -0.07 & Drought & 24 & $0.23 \pm 0.15$ & 0.27 \\
\hline Sediment & 39 & $0.18 \pm 0.27$ & -0.03 & Phytoplankton & 15 & $0.33 \pm 0.19$ & $0.3^{*}$ \\
\hline Younger Dryas & 35 & $0.20 \pm 0.27$ & -0.02 & Chironomids & 13 & $0.39 \pm 0.24$ & $0.35^{*}$ \\
\hline Late Quaternary & 50 & $0.16 \pm 0.25$ & -0.02 & Zooplankton & 36 & $0.19 \pm 0.11$ & $0.37 * *$ \\
\hline Lake level & 18 & $0.30 \pm 0.33$ & -0.02 & Eutrophication & 11 & $0.42 \pm 0.24$ & $0.4 * *$ \\
\hline Pollen & 5 & $0.82 \pm 0.34$ & -0.02 & Late Holocene & 20 & $0.29 \pm 0.18$ & $0.41 * *$ \\
\hline Fire & 38 & $0.19 \pm 0.20$ & -0.01 & Phosphorus & 45 & $0.18 \pm 0.12$ & $0.48 * *$ \\
\hline Hydrology & 27 & $0.22 \pm 0.23$ & -0.01 & Permafrost & 33 & $0.20 \pm 0.13$ & $0.5 * * *$ \\
\hline Human activities & 12 & $0.42 \pm 0.40$ & 0.03 & Nutrients & 43 & $0.18 \pm 0.10$ & $0.53 * * *$ \\
\hline Paleohydrology & 47 & $0.16 \pm 0.16$ & 0.03 & Precipitation & 44 & $0.18 \pm 0.11$ & $0.53 * * *$ \\
\hline Environmental change & 48 & $0.16 \pm 0.17$ & 0.05 & Remote sensing & 21 & $0.28 \pm 0.17$ & $0.6 * * *$ \\
\hline Charcoal & 25 & $0.24 \pm 0.25$ & 0.05 & Cyanobacteria & 17 & $0.30 \pm 0.19$ & $0.62 * * *$ \\
\hline Water quality & 31 & $0.21 \pm 0.21$ & 0.07 & Tibetan Plateau & 30 & $0.22 \pm 0.14$ & $0.66 * * *$ \\
\hline
\end{tabular}

${ }^{\circ}$ Results of Mann-Kendall tests. ${ }^{*} P<0.05 ; * * P<0.01 ; * * * P<0.001$. 

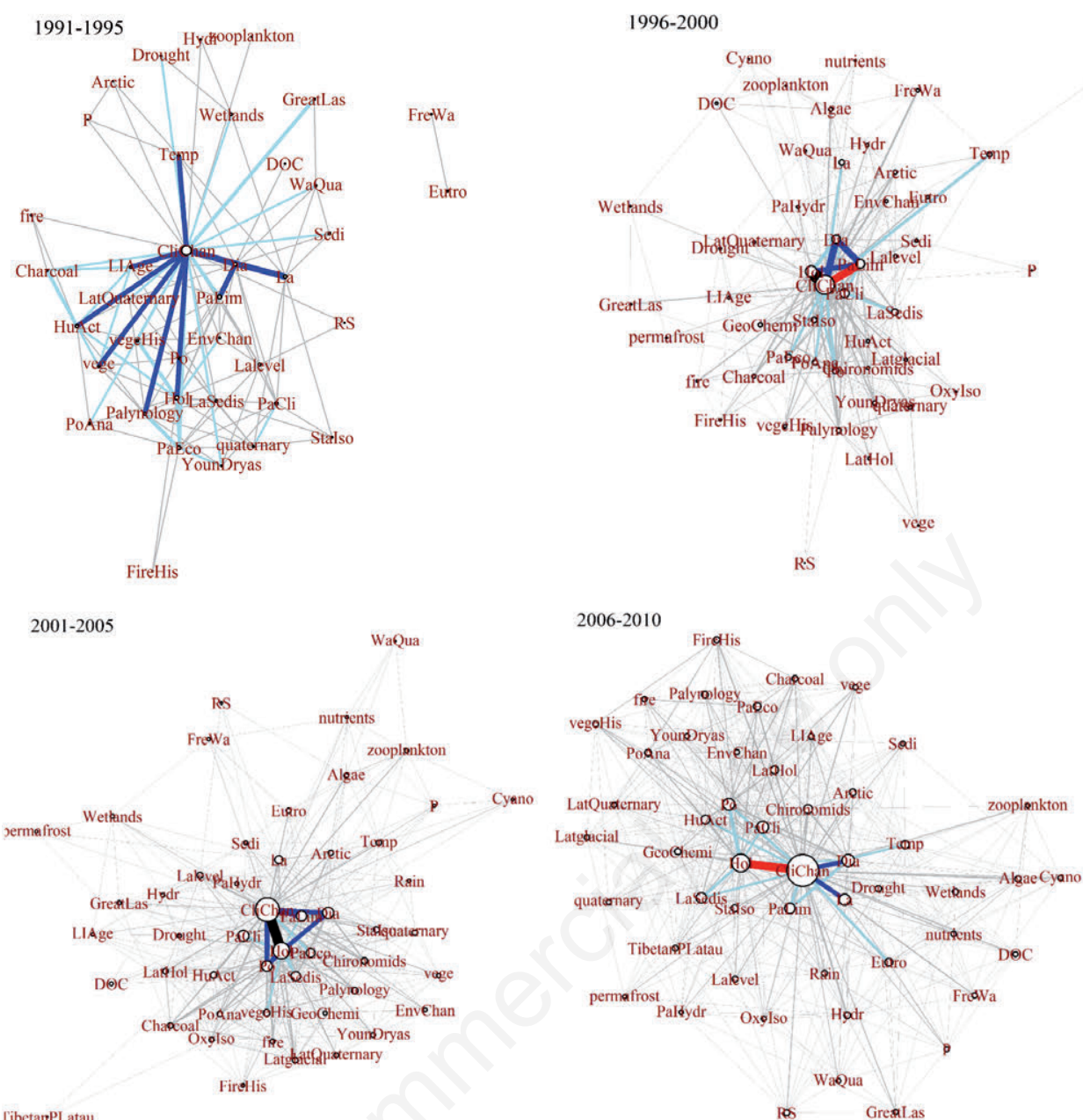

libetarPLatau

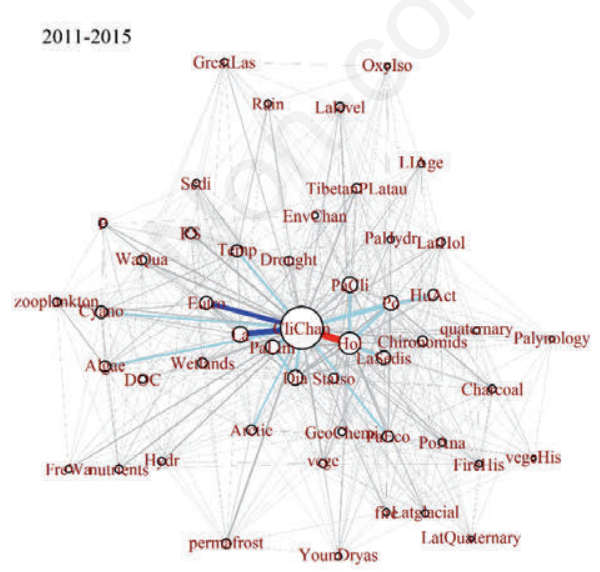

Fig. 3. Visualization of the relationships between the top 50 keywords. The sizes of the nodes represent keyword frequencies. The thicknesses of lines indicate the relationship strength between two keywords (black $>$ red $>$ blue $>$ light blue $>$ gray). In order to make the pictures more readable, we used abbreviation for some author used keywords. Algae, Phytoplankton; CliChan, Climate change; Cyano, Cyanobacteria; Dia, Diatoms; DOC, dissolved organic carbon; EnvChan, Environmental change; Eutro, Eutrophication; FireHis, Fire history; FreWa, Freshwater; From, FromFull; GeoChemi, Geochemistry; GreatLas, Great Lakes; Hol, Holocene; HuAct, human activities; Hydr, Hydrology; La, Lake; Lalevel, Lake level; LaSedis, Lake sediments; Latglacial, Lateglacial; LatHol, late Holocene; LatQuaternary, late Quaternary; LIAge, Little Ice Age; OxyIso, Oxygen isotopes; P, Phosphorus; PaCli, Paclimate; PaEco, Paleoecology; PaHydr, Paleohydrology; PaLim, Paleolimnology; Po, Pollen; PoAna, Pollen analysis; Rain, Precipitation; RS, Remote sensing; Sedi, Sediment; StaIso, Stable isotopes; Temp, Temperature; TibetanPLatau, Tibetan Plateau; vege, vegetation; vegeHis, Vegetation history; WaQua, water quality; YounDryas, Younger Dryas. 
mate change-lake studies attracted increasing attention from scientific communities. Additionally, our study implied a distinct turning point in climate change-lake research between 1991 and 2015. During the early portion of this period, most studies focused on paleolimnology.
Specifically, researchers studied evidence of climate change through lake sediments. Recently, more studies have focused on modern limnology, e.g., the effects of climate change on lake ecosystems.

The abovementioned phenomenon is partly demon-

Tab. 4. The 20 most productive authors and country of their institution.

\begin{tabular}{lcccclccc}
\hline Author name & TP & FA & Country & Author name & TP & FA & Country \\
\hline Smol John P. & 135 & 8 & Canada & Douglas Marianne S. V. & 43 & 0 & Canada \\
\hline Jeppesen Erik & 76 & 13 & Denmark & Vincent Warwick F. & 42 & 6 & Canada \\
\hline Birks H. John B. & 61 & 4 & Norway & Brooks Stephen J. & 40 & 8 & UK \\
\hline Magny Michel & 53 & 22 & France & Grosjean Martin & 40 & 6 & Switzerland \\
\hline Tinner Willy & 52 & 10 & Switzerland & Cumming Brian F. & 39 & 1 & Canada \\
\hline Lotter Andre F. & 49 & 7 & Netherlands & Chen Fahu & 39 & 6 & China \\
\hline Leng Melanie J. & 48 & 2 & UK & Søndergaard Martin & 39 & 1 & Denmark \\
\hline Hu Feng Sheng & 44 & 8 & USA & Anselmetti Flavio S. & 38 & 2 & Switzerland \\
\hline Pienitz Reinhard & 44 & 5 & Canada & Valero-Garces Blas L. & 37 & 5 & Spain \\
\hline Battarbee Richard W. & 44 & 13 & UK & Wolfe Alexander P. & 37 & 6 & Canada \\
\hline
\end{tabular}

TP, total publications; FA, first author publications.

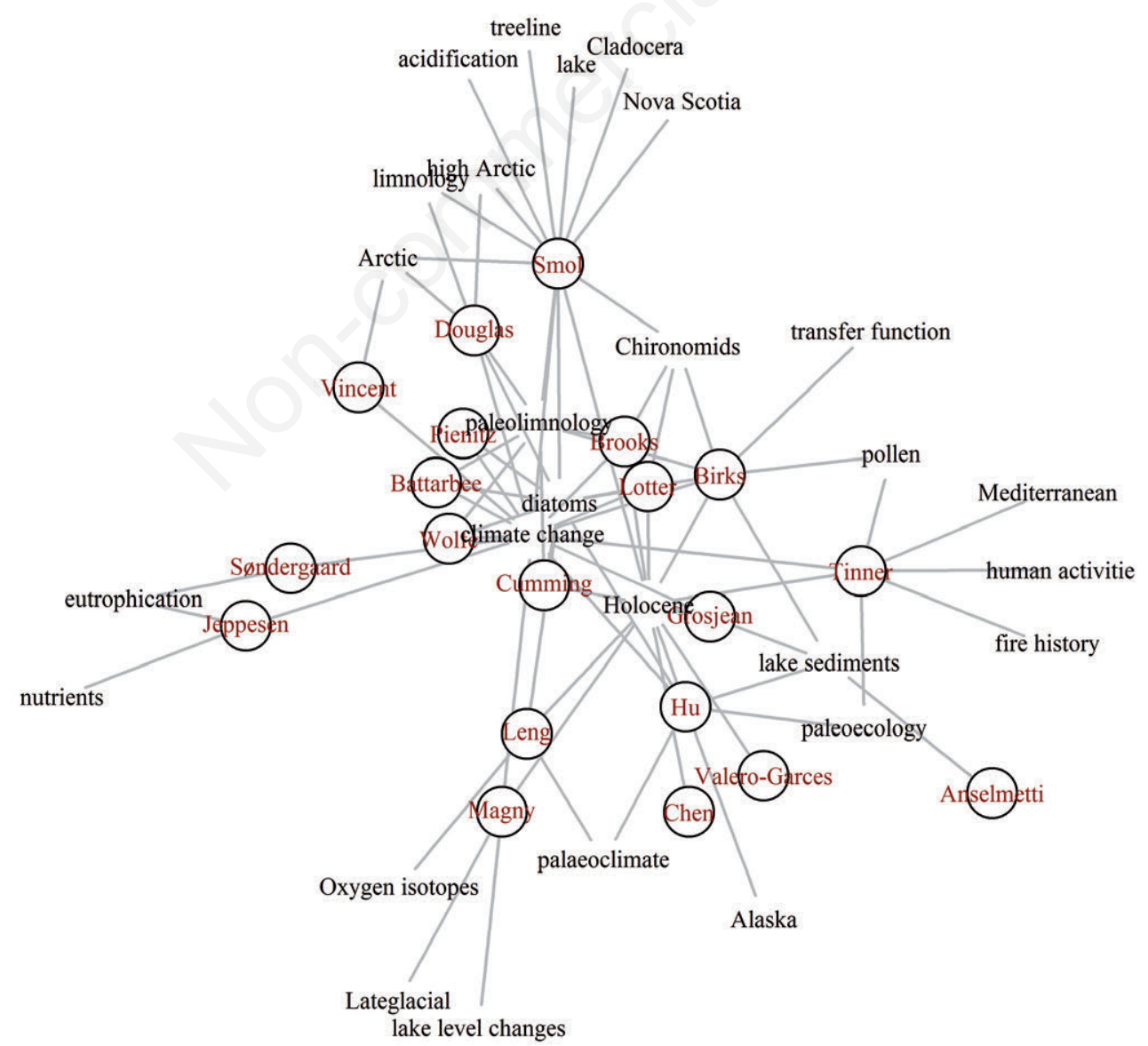

Fig. 4. The most productive authors and their highly related keywords. The full names of authors could be found in Tab. 3 . 
strated by the increasing percentages of publications published in Freshwater Biology, Journal of Great Lakes Research, and Global Change Biology, as well as the numbers of publications by authors with different research interests. In addition, this trend is confirmed by analyzing the author-used keywords. First, words related to "paleo" exhibited apparent decreasing trends. Researchers used paleolimnology to reconstruct ancient climates and learn about the changing climate. However, after intensive studies, we have realized that climate change is largely asso-

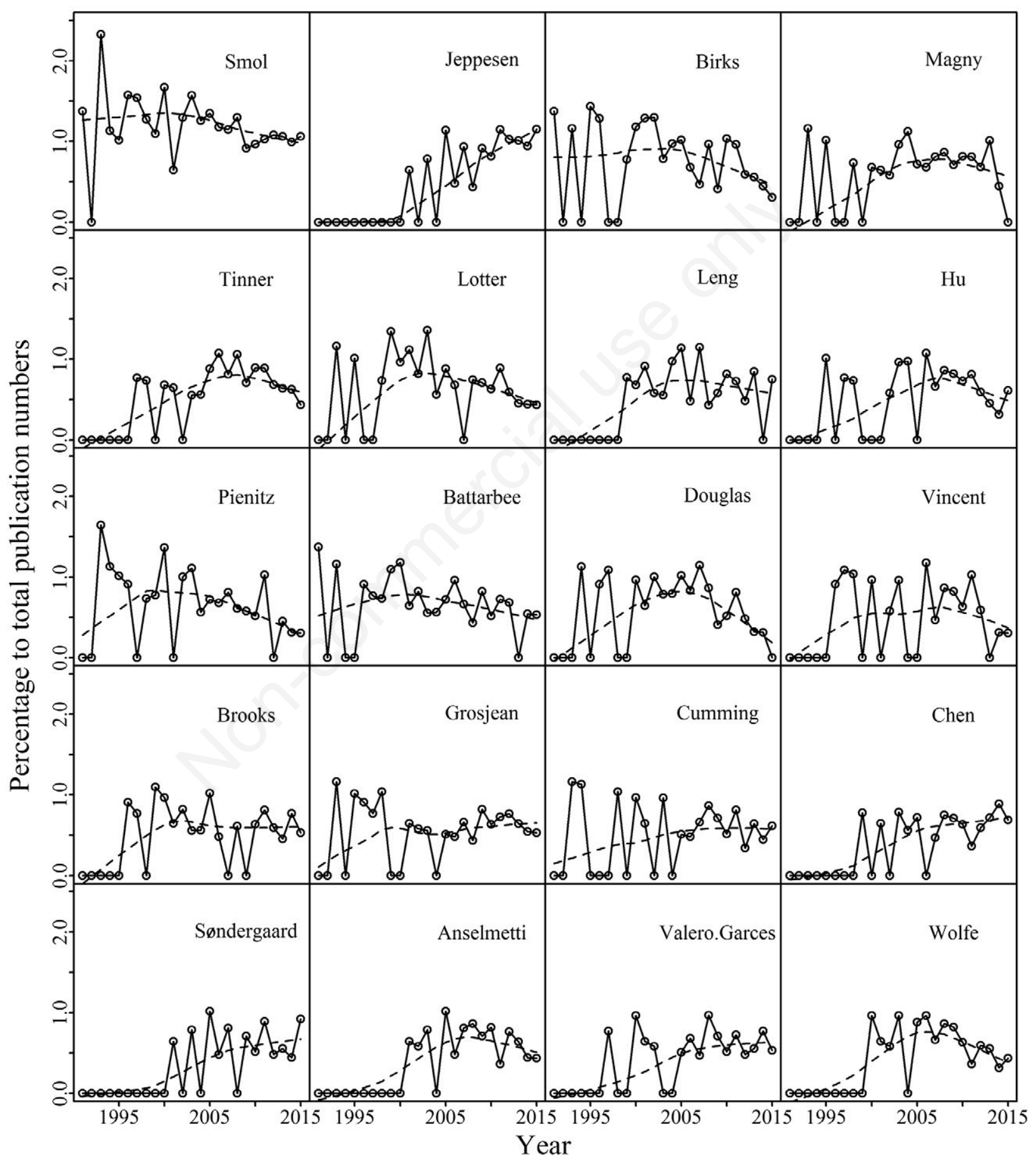

Fig. 5. Trends of percentage of papers published by each author compared to the total papers published. The full names of authors could be found in Tab. 3 . 
ciated with global warming over the last century (Stocker et al., 2013). This may be the most important reason why keyword trends related to "paleo-" have decreased. Lakes provide key ecosystem services for the growth and survival of human populations. They are susceptible to environmental changes, and there is an increasing demand to understand the responses of lake ecosystems to climate change. This may be the main reason why keyword trends related to eutrophication have increased.

According to our results, the relationship between eutrophication and climate change increased. Eutrophication is an ecosystem's response to the addition of artificial or natural nutrients, mainly phosphates, to an aquatic system through detergents, fertilizers, or sewage. Eutrophication can cause phytoplankton increases or "blooms" in water bodies in response to increased levels of nutrients. Negative environmental effects may include hypoxia, which can kill aquatic animals. Recently, studies have suggested that increasing water temperature may increase primary production, favoring the recurrence of cyanobacterial blooms (Paerl and Huisman, 2008). Additionally, climate change can contribute to eutrophication in lakes by increasing nutrient loading, particularly nitrogen and phosphorus loading through runoff, which is enhanced by increased precipitation (Jeppesen et al., 2009, 2011).

Since Jeppesen was the second most productive author and whose research interest focus on modern limnology, we use Jeppesen's publication trend as an example to illustrate the increasing trends for studies on the effects of climate change on lakes. The publication numbers increased significantly, especially since 2005 (Fig. 6). The most frequent keywords before 2005 were eutrophication, zooplankton, fish and shallow lakes, which mainly related to lake restoration with biomanipulation. Climate change did not appear in author used keywords among his publication until 2006 and its frequency of occurrence raised rapidly since 2011 (Fig. 7).

Studies regarding aquatic ecosystems have mainly fo-

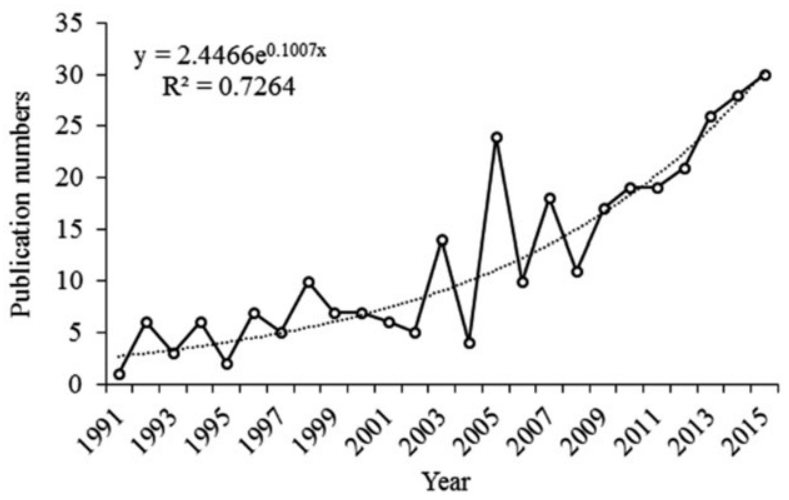

Fig 6. Publication numbers each year of Erik Jeppesen since 1991 until 2015. cused on three aspects: aquatic organisms, aquatic environments and aquatic ecosystem conditions. Compared to other organisms, such as zooplankton, bacteria, fishes, etc., phytoplankton has received more attention in studies related to climate change. This is potentially because phytoplankton communities exhibit stronger responses to environmental changes than do other communities, such as bacterioplankton (Liu et al., 2015).

Cyanobacterial dominance in lakes has received considerable attention in the past because of frequent bloom formation in lakes with higher trophic levels. Bloom formation may result in surface scums. These scums produce unpleasant tastes and odors and are unsatisfactory food sources for many organisms in the food-web (Dokulil and Teubner, 2000). Although it is clear that increased nutrient inputs are the prime cause of the heavy selective pressure on phytoplankton, based on abundant studies, climate warming may enhance cyanobacterial dominance globally (Jöhnk et al., 2008; Kösten et al., 2012; Deng et al., 2016).

In this paper, we have explained the increasing trends associated with several keywords from a cause-result perspective. However, modern monitoring results can also be used as indicators of climate change (Adrian et al., 2009). Phytoplankton and zooplankton communities in many lakes have been relatively well documented over extended periods, and these records are useful for extracting climate related responses (Adrian et al., 2009). Phytoplankton phenology can provide a good reflection of climatic shifts (Straile, 2002; Blenckner et al., 2007). Changes in species compositions have been used as climate indicators on longer geological timescales (Rühland et al., 2008). Although we made an extensive search by Web of Science, the number of journals included by SCI-Expanded database is increasing along years. For instance, the Journal of Limnology was included in Web of Science since 2007. The Journal of Limnology devoted a special issue on climate change effects on alpine lakes (Lami et al., 2000), and the

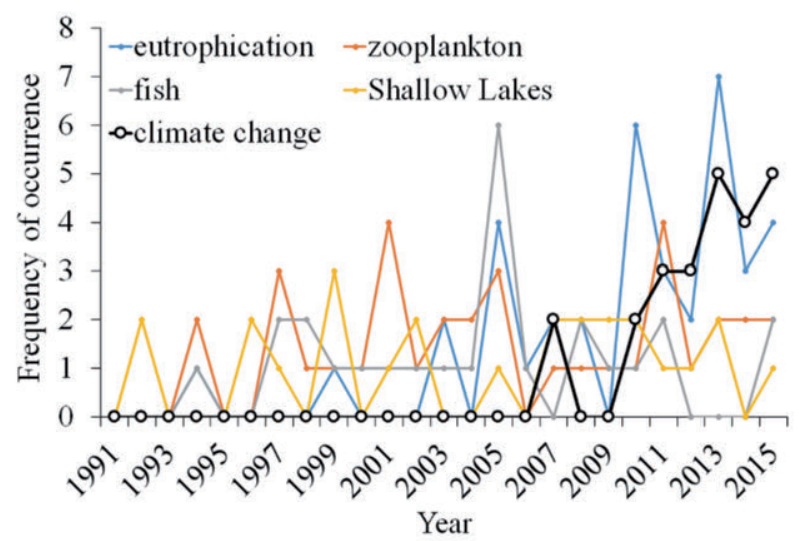

Fig. 7. The top 5 frequent author used keywords among Erik Jeppesen's publications and their trends during 1991 and 2015. 
data was not included in the results from Web of Science. This might bring bias to our conclusions on journal rankings. However, our analysis included journals, authors and author used keywords as well, and our results systematically revealed the recent research status and developing trends associated with climate change-lake research.

Clearly, scientific communities were initially trying to find evidence of climate change. Recently, researchers have focused on the effects of climate change on lake ecosystems. In many early studies, only a single variable was taken into account. However, there is growing concern that interactions between climate warming and eutrophication may affect aquatic ecosystems globally (Deng et al., 2014). Studies based on large samples indicated that lakes' responses to climate change were highly dependent on their trophic levels (Rigosi et al., 2014). In the near future, studies should focus on the interactive effects of climate change and eutrophication, or other environmental variables, on lake ecosystems.

IPCC reports have always included special reports discussing climate change mitigation and the underlying technological, economic, and institutional requirements (Edenhofer et al., 2014). Hence, based on the known threats to lake ecosystems under current climate scenarios, such as risks associated with invasions, harmful blooms, and toxins, scientists should attempt to find a solution that mitigates the negative effects of climate change (Moss et $a l ., 2011)$. For example, it was suggested that nutrient inputs will likely need to be reduced more aggressively in the future compared to inputs projected for today's climate (Paerl and Paul, 2012), as higher temperatures can cause cyanobacterial blooms at lower nutrient input rates and concentrations compared to the rates and concentrations required at lower temperatures.

It is widely recognized that warming increases eutrophication symptoms; however, eutrophication might also promote climate change (Moss et al., 2011). This might be possible because eutrophication effects on greenhouse gas fluxes might override those of climate warming (Davidson et al., 2015). Warming-induced eutrophication will render them even more likely to release greenhouse gases as algal crops increase, sediments become intensely anaerobic, more heat is absorbed, and respiration rates accelerate (Moss et al., 2011). These trends represent potential research topics in the near future.

\section{CONCLUSIONS}

A bibliometric method was used in our analysis, and the results indicated increasing trends associated with climate change studies of lakes from 1991 to 2015. In addition, our study also implied a distinct turning point in climate change-lake research between 1991 and 2015. In early years, researchers were mainly searching for the evidence of climate change from lake sediments by using traditional technologies, such as reflecting ancient climate using the information recorded by diatom or pollen in the sediments. Recently, more studies have focused on modern limnology, e.g., the effects of climate change on lake ecosystems, this was also documented by the increasing relationship between eutrophication and climate change.

\section{ACKNOWLEDGMENTS}

Thanks to Prof. Ge Yu for her early review and help in improving our manuscript. This study was jointly funded by the National Natural Science Foundation of China (grants 41501215), International Science \& Technology Cooperation Program of China (2014DFG91780), the CAS/SAFEA International Partnership Program for Creative Research Teams (KZZD-EW-TZ-08), the National Natural Science Foundation of China (grants 41621002, 41230744 and 41271355). The authors also would like to thank the two anonymous reviewers for their useful comments and constructive suggestions.

\section{REFERENCES}

Adrian R, O'Reilly CM, Zagarese H, Baines SB, Hessen DO, Keller W, Livingstone DM, Sommaruga R, Straile D, Van Donk E, 2009. Lakes as sentinels of climate change. Limnol. Oceanogr. 54:2283-2297.

Barbosa FG, Schneck F, 2015. Characteristics of the top-cited papers in species distribution predictive models. Ecol. Model. 313:77-83.

Blenckner T, Adrian R, Livingstone DM, Jennings E, Weyhenmeyer GA, George DG, Jankowski T, Järvinen M, Aonghusa CN, Nõges T, 2007. Large-scale climatic signatures in lakes across Europe: a meta-analysis. Global Change Biol. 13:1314-1326.

Carpenter SR, Benson BJ, Biggs R, Chipman JW, Foley JA, Golding SA, Hammer RB, Hanson PC, Johnson PTJ, Kamarainen AM, 2007. Understanding regional change: Comparison of two lake districts. Bioscience 86:2737-2750.

Csardi G, Nepusz T, 2006. The igraph software package for complex network research, InterJournal, Complex Systems. http://igraph.org.

Davidson TA, Audet J, Svenning JC, Lauridsen TL, Søndergaard M, Landkildehus F, Larsen SE, Jeppesen E, 2015. Eutrophication effects on greenhouse gas fluxes from shallow lake mesocosms override those of climate warming. Global Change Biol. 21:343-360.

Deng J, Qin B, Paerl HW, Zhang Y, Wu P, Ma J, Chen Y, 2014. Effects of nutrients, temperature and their interactions on spring phytoplankton community succession in Lake Taihu, China. PLoS One 9:e113960.

Deng J, Qin B, Sarvala J, Salmaso N, Zhu G, Ventelä AM, Zhang Y, Gao G, Nurminen L, Kirkkala T, 2016. Phytoplankton assemblages respond differently to climate warming and eutrophication: A case study from Pyhäjärvi and Taihu. J. Great Lakes Res. 42:386-396.

Dokulil MT, Teubner K, 2000. Cyanobacterial dominance in lakes. Hydrobiologia 438:1-12.

Duan H, Ma R, Xu X, Kong F, Zhang S, Kong W, Hao J, Shang $\mathrm{L}, 2009$. Two-decade reconstruction of algal blooms in 
China's Lake Taihu. Environ. Sci. Technol. 43:3522-3528.

Edenhofer O, Pichs-Madruga R, Sokona Y, 2014. Climate change 2014. Mitigation of climate change -Summary for policymakers. Environmental Policy Collection.

Ellegaard O, Wallin JA, 2015. The bibliometric analysis of scholarly production: How great is the impact? Scientometrics 105:1809-1831.

Haunschild R, Bornmann L, Marx W, 2016. Climate change research in view of bibliometrics. PLoS One 11: e0160393.

Ho YS, 2007. Bibliometric analysis of adsorption technology in environmental science. J. Environ. Prot. Sci. 1:1-11.

Ho YS, Kahn M, 2014. A bibliometric study of highly cited reviews in the Science Citation Index Expanded ${ }^{\mathrm{TM}}$. J. Assoc. Inf. Sci. Tech. 65:372-385.

Jöhnk KD, Huisman J, Sharples J, Sommeijer B, Visser PM, Stroom JM, 2008. Summer heatwaves promote blooms of harmful cyanobacteria. Global Change Biol. 14:495-512.

Jensen HS, Andersen FO, 1992. Importance of temperature, nitrate, and $\mathrm{pH}$ for phosphate release from aerobic sediments of four shallow, eutrophic lakes. Limnol. Oceanogr 37:577-589.

Jeppesen E, Kronvang B, Meerhoff M, Sondergaard M, Hansen KM, Andersen HE, Lauridsen TL, Liboriussen L, Beklioglu M, Ozen A, Olesen JE, 2009. Climate change effects on runoff, catchment phosphorus loading and lake ecological state, and potential adaptations. J. Environ. Qual. 38, 1930-1941.

Jeppesen E, Kronvang B, Olesen JE, Audet J, Sondergaard M, Hoffmann CC, Andersen HE, Lauridsen TL, Liboriussen L, Larsen SE, Beklioglu M, Meerhoff M, Ozen A, Ozkan K, 2011. Climate change effects on nitrogen loading from cultivated catchments in Europe: implications for nitrogen retention, ecological state of lakes and adaptation. Hydrobiologia 663:1-21.

Kösten S, Huszar VL, Becares E, Costa LS, Donk E, Hansson LA, Jeppesen E, Kruk C, Lacerot G, Mazzeo N, 2012. Warmer climates boost cyanobacterial dominance in shallow lakes. Global Change Biol. 18:118-126.

Khan MA, Ho YS, 2012. Top-cited articles in environmental sciences: Merits and demerits of citation analysis. Sci. Total Environ. 431:122-127.

Komatsu E, Fukushima T, Harasawa H, 2007. A modeling approach to forecast the effect of long-term climate change on lake water quality. Ecol. Model. 209:351-366.

Lami A, Cameron N, Korhola A, 2000. Preface for climatic variability and ecosystem dynamics at remote mountain lakes. J. Limnol. 59(s1):a-b. Doi: 10.4081/jlimnol.2000.s1.a

Larsen PO, Ins MV, 2010. The rate of growth in scientific publication and the decline in coverage provided by Science Citation Index. Scientometrics 84:575-603.

Li JF, Wang MH, Ho YS, 2011. Trends in research on global climate change: A Science Citation Index Expanded-based analysis. Glob. Planet. Change 77:13-20.

Li W, Zhao Y, 2015. Bibliometric analysis of global environmental assessment research in a 20 -year period. Environ. Impact Assess. Rev. 50:158-166.

Liu L, Yang J, Lv H, Yu X, Wilkinson DM, Yang J, 2015. Phytoplankton communities exhibit a stronger response to environmental changes than bacterioplankton in three subtropical reservoirs. Environ. Sci. Technol. 49:10850-10858.

Liu X, Zhang L, Song H, 2011. Global biodiversity research during 1900-2009: A bibliometric analysis. Biodivers. Conserv. 20:807-826.

Marx W, Haunschild R, Thor A, Bornmann L, 2017. Which early works are cited most frequently in climate change research literature? A bibliometric approach based on Reference Publication Year Spectroscopy. Scientometrics 110:335-353.

McLeod AI, 2011. Kendall: Kendall rank correlation and MannKendall trend test. R package version 2.2. https://CRAN.Rproject.org/package $=$ Kendall.

Moss B, Kosten S, Meerhof M, Battarbee R, Jeppesen E, Mazzeo N, Havens K, Lacerot G, Liu Z, De Meester L, 2011. Allied attack: climate change and eutrophication. Inland Waters 1:101-105.

Paerl HW, Huisman J, 2008. Blooms like it hot. Science 320: 57-58.

Paerl HW, Pau VJ, 2012. Climate change: links to global expansion of harmful cyanobacteria. Water Res. 46:13491363.

Pham SV, Leavitt PR, McGowan S, Peres-Neto P, 2008. Spatial variability of climate and land-use effects on lakes of the northern Great Plains. Limnol. Oceanogr. 53:728-742.

Posch T, Köster O, Salcher MM, Pernthaler J, 2012. Harmful filamentous cyanobacteria favoured by reduced water turnover with lake warming. Nat. Clim. Change 2:809-813.

Pritchard A, 1969. Statistical bibliography or bibliometrics? J. Doc. 25:348-349.

R Core Team, 2015. R: A language and environment for statistical computing. R Foundation for Statistical Computing, Vienna, Austria. Available from: https://www.R-project.org/

Rühland K, Paterson AM, Smol JP, 2008. Hemispheric-scale patterns of climate-related shifts in planktonic diatoms from North American and European lakes. Global Change Biol. 14:2740-2754.

Rigosi A, Carey CC, Ibelings BW, Brookes JD, 2014. The interaction between climate warming and eutrophication to promote cyanobacteria is dependent on trophic state and varies among taxa. Limnol. Oceanogr. 59:99-114.

Salmaso N, 2011. Interactions between nutrient availability and climatic fluctuations as determinants of the long-term phytoplankton community changes in Lake Garda, Northern Italy. Hydrobiologia 660:59-68.

Stocker T, Qin D, Plattner G, Tignor M, Allen S, Boschung J, Nauels A, Xia Y, Bex B, Midgley B, 2013. IPCC, 2013: climate change 2013: the physical science basis. Contribution of working group I to the fifth assessment report of the intergovernmental panel on climate change.

Straile D, 2002. North Atlantic Oscillation synchronizes foodweb interactions in central European lakes. P. Roy. Soc. Lond. B-Biol. 269:391-395.

van Raan AFJ, 1996. Advanced bibliometric methods as quantitative core of peer review based evaluation and foresight exercises. Scientometrics 36:397-420.

van Raan AFJ, 2009. For your citations only? Hot topics in bibliometric analysis. Meas. Interdiscipl. Res. Perspect. 3:50-62.

Wagner C, Adrian R, 2009. Cyanobacteria dominance: quantifying the effects of climate change. Limnol. Oceanogr. 54:2460-2468.

Walther GR, Post E, Convey P, Menzel A, Parmesan C, Beebee TJ, Fromentin JM, Hoegh-Guldberg O, Bairlein F, 2002. Ecological responses to recent climate change. Nature 416:389-395.

Zhang M, Duan HT, Shi XL, Yu Y, Kong FX, 2012. Contributions of meteorology to the phenology of cyanobacterial blooms: implications for future climate change. Water Res. 46:442-452.

Zhi W, Ji G, 2012. Constructed wetlands, 1991-2011: A review of research development, current trends, and future directions. Sci. Total Environ. 441:19-27. 